\title{
Epithelial Cell Coculture Models for Studying Infectious Diseases: Benefits and Limitations
}

\author{
Benjamin L. Duell, ${ }^{1}$ Allan W. Cripps, ${ }^{1}$ Mark A. Schembri, ${ }^{2}$ and Glen C. Ulett ${ }^{1}$ \\ ${ }^{1}$ School of Medical Sciences and Griffith Health Institute, Centre for Medicine and Oral Health, Griffith University, \\ Southport, QLD 4222, Australia \\ ${ }^{2}$ School of Chemistry and Molecular Biosciences, the University of Queensland, QLD 4072, Australia \\ Correspondence should be addressed to Glen C. Ulett, g.ulett@griffith.edu.au
}

Received 4 May 2011; Revised 19 July 2011; Accepted 27 July 2011

Academic Editor: Anthony L. DeVico

Copyright (๑) 2011 Benjamin L. Duell et al. This is an open access article distributed under the Creative Commons Attribution License, which permits unrestricted use, distribution, and reproduction in any medium, provided the original work is properly cited.

\begin{abstract}
Countless in vitro cell culture models based on the use of epithelial cell types of single lineages have been characterized and have provided insight into the mechanisms of infection for various microbial pathogens. Diverse culture models based on diseaserelevant mucosal epithelial cell types derived from gastrointestinal, genitourinary, and pulmonary organ systems have delineated many key host-pathogen interactions that underlie viral, parasitic, and bacterial disease pathogenesis. An alternative to single lineage epithelial cell monoculture, which offers more flexibility and can overcome some of the limitations of epithelial cell culture models based on only single cell types, is coculture of epithelial cells with other host cell types. Various coculture models have been described, which incorporate epithelial cell types in culture combination with a wide range of other cell types including neutrophils, eosinophils, monocytes, and lymphocytes. This paper will summarize current models of epithelial cell coculture and will discuss the benefits and limitations of epithelial cell coculture for studying host-pathogen dynamics in infectious diseases.
\end{abstract}

\section{Epithelial Cell Monoculture for Modelling Disease}

The defining event for most infections occurs during the initial phase of the host response to colonisation by a pathogen [1] or commensal organism [2]. In studying host responses there is a tendency to focus on the cell types that comprise the biological barriers to microbes to uncover the host signalling events and virulence traits that are involved in the initial phase of disease. Cell culture models can compartmentalize and define the broad range of molecular mechanisms that underlie strategies of microbial virulence such as host receptor ligand binding and can afford critical insight in what drives host defence strategies. Many diverse, sometimes intricate, epithelial cell culture models based on the use of single lineages of cells, also known as monocultures, have been characterized under carefully optimized in vitro conditions. These have provided the basis for our current understanding of many host-pathogen interactions such as those involving herpes and hepatitis viruses $[3,4]$, the malaria parasite $[5,6]$, and leading bacterial pathogens including Haemophilus influenzae and Campylobacter jejuni [7, 8]. Monocultures have also provided much of our current understanding of how $M$ cells sample bacteria from the lumen of mucosal sites that initiates innate immune defence [9-11]. In studying host responses to microorganisms as well as the virulence traits employed during host-pathogen interactions the limitations in extrapolating functional mechanisms in cell culture models that are based on only single cell types are well known. Most evidently, these limitations reflect the inherent inability of single lineage monoculture systems to model the complex biological processes that occur in tissues in vivo. These processes comprise multiple cell types that often necessarily interact to mediate effective antimicrobial defence $[12,13]$ and inflammatory reactions $[14,15]$. Widespread use of monolayers and suspensions of single cell types in vitro was driven in part by difficulties in identifying discrete functional pathways using in vivo models.

The main advantage of in vitro models based on single cell types lies in their ability to provide key information on 
a particular cell type's reaction to an infectious microbe. Monocultures provide an efficient and economical means of teasing apart a wide range of experimental variables given the versatility of homogeneous cell populations in vitro versus the economic and ethical constraints of in vivo models. However, cell culture models consisting of one cell type reflect few biological host systems, given the multiple intercellular communication networks that exist in organs and the vasculature and lymphatics. Monocultures are unable to replicate critical processes that drive immune responses to pathogens such as antigen-presenting celllymphocyte communication [16]. Monocyte-derived dendritic cells challenged with Burkholderia pseudomallei, for example, require contact with other cell types to generate immune responses [17]. Seropositive T cells combined with dendritic cells mediate gamma interferon production in $\mathrm{CD}^{+}{ }^{+} \mathrm{T}$ cells and granzyme $\mathrm{B}$ in $\mathrm{CD} 8^{+} \mathrm{T}$ cells in this case [17]. Thus, despite their widespread use and noted benefits monoculture systems are not an ideal foundation for in vitro modelling of infectious processes.

An in vitro alternative to monoculture is coculture of multiple cell types including most commonly epithelial cells. This approach is being used with increasing frequency as a solution to bridge the gap between overly simplistic single lineage in vitro models and the dynamic biological processes that occur in vivo. Coculturing epithelial cells with other cell types in proportional levels approximated to known tissue constituency have been used to mimic the in situ interactions of various body systems. Such models have been used to study immune defence and have highlighted the effects of neutrophils, eosinophils, monocytes, and lymphocytes on epithelial cell function [18]. These effects appear to occur predominantly through the paracrine signalling actions of cytokines and other chemical mediators [18]. Contactdependent juxtacrine events may also impact coculture phenotypes; however, reports of these have been rarely reported in comparison.

Epithelial cell coculture models have recently been extended to primary cells to define epithelial cell function in immune reactivity to microorganisms. A coculture model of alveolar epithelial cells with monocyte-derived macrophages and dendritic cells, for example, has been used to model alveolar epithelial barriers to microorganisms [19]. Expansion of cocultures through the use of structurally distinct $3 \mathrm{D}$ organotypic systems $[20,21]$ is another area of intense research gaining popularity. These systems utilize free flowing media and complex scaffolds in radial-flow or rotating wall bioreactors. This approach more closely replicates in vivo biology beyond basic coculturing of different cell types with rearrangement of cells into proto-organic structures $[20,21]$. Moreover, recent data indicate that these systems offer new ways to study signalling events and drug interactions [21]. Stationary 3D models have also been used to study dynamics of cell migration through cell layers and suspensions [22]. Highly complex organotypic rotating models that incorporate synthetic surfaces and matrices have also been used to explore permeability properties [23]. However, nonscaffolded cocultures provide a compromise in terms of advantages and limitations because they are technically uncomplicated but provide capacity to model intercellular interactions. An overview of nonscaffolded epithelial cell coculture models that have been described in the literature is illustrated in Figure 1.

\section{Benefits and Limitations of Epithelial Cell Coculture}

The range of coculture models using continuous epithelial cell lines is diverse. Many tend to incorporate epithelial cells lines in short-term assays (less than $24 \mathrm{~h}$ ) to replicate biological barriers and interactions with membranous surfaces [24], or immune responses and host defence [18]. One benefit of coculture compared to monoculture is its capacity to better reflect the in vivo biology of cytokines, growth factors, and transcriptional regulators activated or repressed in response to disease. For example, a study of inflammatory mechanisms underlying colon cancer revealed monocytederived IL-10 directly effects intestinal epithelial cell IL-6 synthesis [25]. This was thought to contribute to disease progression through mucin production and cell migration [25]. In terms of wound repair during disease and regeneration of biological barriers coculture models have been useful for defining novel epithelial cell function. Investigations of the epithelium in epidermal tissue showed that laminin5 anchors basal epithelial cells to the extra cellular matrix (ECM) but requires fibroblasts to mediate cleavage of the mature peptide [26]. This promotes incorporation into the ECM to enable stronger epithelial layer attachment [26]. Cocultures analysing cell types for epithelial regeneration have also indicated that fibroblasts stimulate repair of a Caco2 monolayer more efficiently than a monolayer alone after damage to the cells [27]. Collectively, this illustrates the contributions of fibroblasts in epithelial barrier regeneration and underscores the benefits of cocultures for study of wound repair.

In addition to wound repair, an area where coculture models have led to major advances is embryotrophic coculturing [28]. These models have reconstructed uterine tissue in vitro by using primary and immortalized cell lines and conditional media to host embryonic development [29]. In nonscaffolded models reductive effects of fibroblasts, epithelial cells and other uterine cell types have been demonstrated to confer benefits on embryo maturation. This appears to occur through removal of defined media components and concentrations of byproducts such as oxidants, free radicals, and cytokines. Beneficial effects through the provision of various proteins and growth factors were reported to enhance viability in this model [29]. A noted limitation in these studies, however, was the use of serum, which negatively influenced embryonic outcomes. This led to multiphase coculture systems that utilized chambers between sections within cocultures to minimize the impact of media components. Serum-free media was identified as a possible alternative to address the divergent nutritional requirements of the different cells in this system [29].

2.1. Media and Continuous Cell Lines for Epithelial Cell Coculture. Shifts in concentrations of media components such as 


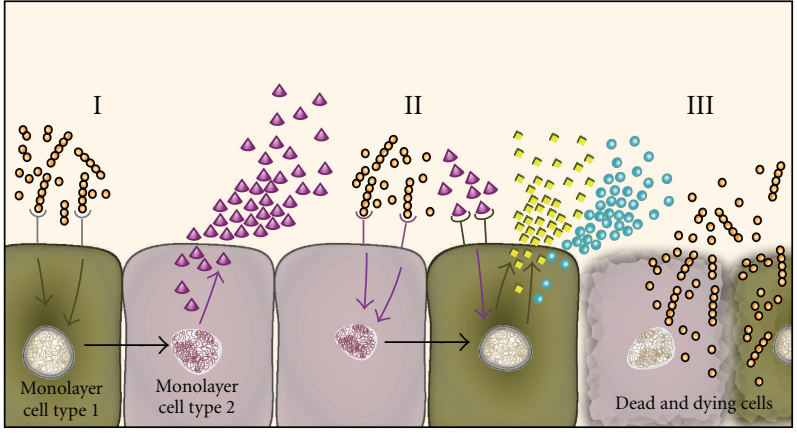

(a)

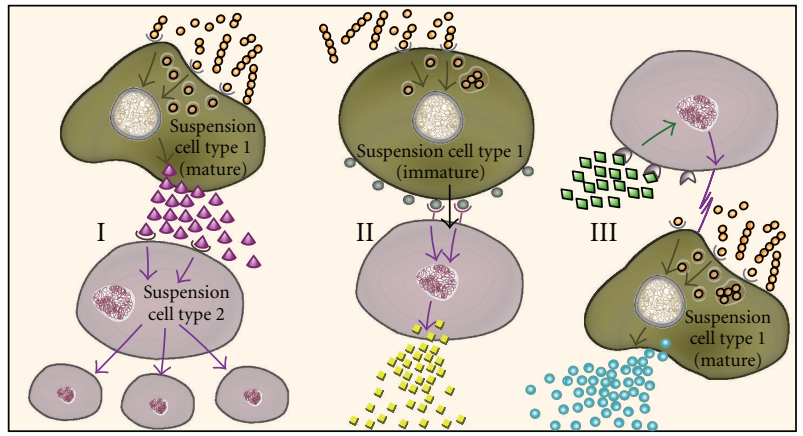

(b)

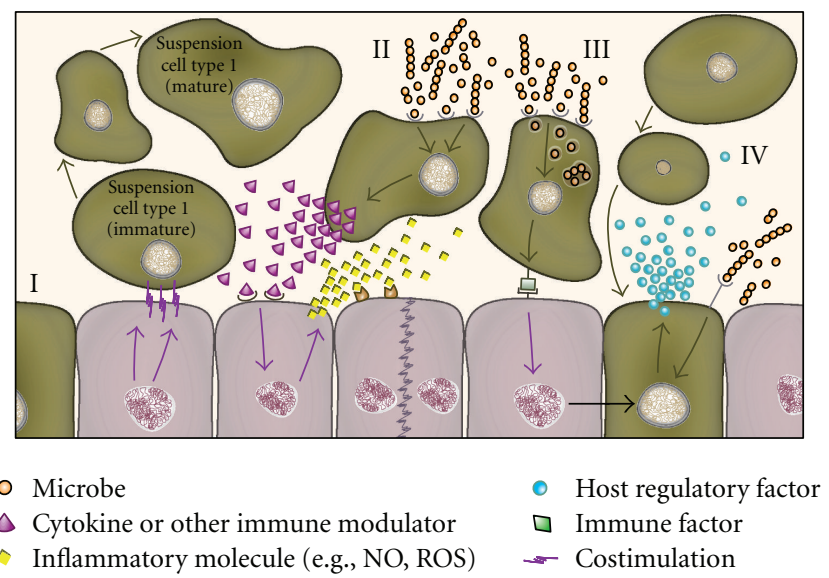

(c)

Figure 1: Examples of coculture models for the study of infection. A. Monolayer cocultures typically incorporate epithelial cells and another adherent cell type(s) and these detect microbes (I) and signal via juxtacrine mechanisms (black arrow) to cells in the monolayer to induce synthesis of immune factors and cytokines. Microbes that bind or invade epithelial cells may induce signals from the partner cell types in the monolayer, which can release inflammatory molecules (II) such as nitric oxide (NO) or reactive oxygen species (ROS). In models that utilize viable microbes overgrowth can lead to cytotoxicity of host cells in the monolayer (III) and may limit the study. B. Suspension cocultures often utilize phagocytes that ingest microbes and signal other cells to proliferate (I). Suspension coculture models sometimes use dynamic conditions such as rolling and may incorporate immature or mature versions of cell lineages such as monocytes or macrophages. Intercellular signalling can occur via juxtacrine pathways (black arrow) where receptors are ligated and can lead to the induction of inflammatory molecules (II). Alternatively, cells may respond to immune factors as co-stimulatory molecules that are required for optimal responses to microbes (III) such as production of regulatory factors. C. Mixed cocultures typically utilize adherent monolayers in combination with a suspension cell type(s), which can respond to co-stimulation by differentiation (I). Microbe binding to suspension cells may lead to cytokine/immune factor signalling of the adherent cells to induce the secretion of inflammatory molecules by the monolayer (II). Phagocytes present in the coculture may ingest microbes and signal to the adherent cells via an unknown receptor mechanism to promote juxtacrine signalling between cells (black arrow) as a means to trigger downstream regulatory factors (III). Microbe binding to adherent cells may stimulate paracrine signalling to suspension cells, recruiting them towards the monolayer (IV).

glucose, amino acids, serum, and vitamins can occur more rapidly in cocultures than monocultures due to increased metabolism and byproduct accumulation. For example, lactic acid, which lowers $\mathrm{pH}$ and inhibits key glycosylating enzymes, inhibits cell growth [30]. Modifying media by alternative carbohydrates can stabilize $\mathrm{pH}$ and, when combined with bicarbonate- $\mathrm{CO}_{2}$ buffering, can minimize the impact of increased metabolism [30]. Increased metabolism of infected cocultures is also important to consider, particularly for receptor and glycosylated microbial-binding target studies. These targets can be affected by media components and byproducts [31-33]. For example, nutrient consumption and byproduct accumulation decreases protein glycosylation [30] but glycan structures of glycoproteins on host cells can be important for microbe binding [34]. Where glycoproteins act as ligands for microbe adherence such as for H. Pylori [35], deregulated metabolism and modified glycoprotein availability may introduce model artefacts. Secretion of basal signalling factors leads to their accumulation in coculture more rapidly and this can also affect the function of certain cell types [36]. Metabolic breakdown of glutamine to ammonia, for example, inhibits cell growth at high $\mathrm{pH}$, and can decrease sialylation and change glycan structure [30]. Accumulation of byproducts and depletion of glutamine would occur more rapidly where the microorganisms under study proactively utilize glutamine for metabolism [37]. 
Finally, microbial respiration may also affect the biology of epithelial cell cocultures; dissolved oxygen, for example, influences galactosylation [30] and microbial adherence can be affected by the level of dissolved oxygen in culture media [38]. Where epithelial cell lines are studied in longer-term assays (more than $24 \mathrm{~h}$ ) the impact of media requirements is even more important. It is notable that coculture systems may limit the movements of molecules over time when studied under organotypic conditions [29].

A limitation of most cocultures described to date is the effects of continuous cell lines, which often display phenotypes not observed in primary cells [39]. An example is varied expression of cytokines and cell surface markers [40, 41]. Murine gastric epithelial cells show different levels of expression of cathepsin-X, a cell marker with a putative immunological interaction with macrophages, depending on whether the gastric epithelial cells are primarily derived or immortalized [39]. Strong cathepsin-X expression in primary cells contrasts with undetectable levels in immortalised cells, which leads to lesser attachment of $H$. pylori. This has a major effect on the outcome of host-pathogen interactions in this model [39]. Another well-characterized phenotypic disconnect between primary and continuous epithelial cells is bladder uroepithelial cells. While primary mammalian uroepithelial cells express uroplakin proteins such as UPIa, UPIb, UPII, and UPIII on their surface [42, 43], commonly used carcinoma-derived immortalized uroepithelial cell lines used to study adherence of and inflammatory reactions to uropathogenic Escherichia coli $[44,45]$ and streptococci [46] mostly do not express these proteins [47-50]. Ecadherin and cingulin expression also differs in monolayers versus primary cells [50]. Despite these known artefacts of continuous epithelial cell lines, their use in coculture offers tangible benefits compared to primary cells. Most epithelial cell lines are robust, are easily propagated, and they may be preferable for long-term assays where temporal continuity and avoidance of repeated collection of primary cells are important. They are more suited to studies where isolation of primary cells is technically demanding or time consuming. The risk of cross-contamination between cell lines is, however, increased with concurrent use of multiple cell lines for coculture as demonstrated for HeLa epithelial cells [51]. Thus, regular maintenance of multiple cell lines demands increased adherence to strict work-flow practices, and regular quality control checks to ensure the integrity of continuous cell lines [52].

Finally, the maintenance of cell lines for coculture requires repeated passaging, and this routine activity can introduce artefacts in coculture. Trypsin protease, for example, used to detach cells, causes physiological changes including upregulation of protein production [53], membrane protein and sialic acid modification [54], proliferation [55], and activation of membrane channels [56]. Application of golgi-blockers such as brefeldin A [57] in coculture to retain intracellular products such as cytokines can disrupt other cellular functions by prohibiting exocytosis of vital proteins and may even cause cell death [58]. Thus, treatment agents used for the regular maintenance of cells lines for coculture and their treatment and analysis need to be carefully selected so that experimental artefacts in coculture systems are minimized.

\subsection{Epithelial Cell Cocultures for Immunology and Organ-} otypic Models. Coculturing of epithelial cells in an immunological context has provided key information on the influence of individual cell types towards others in proximity. For example, exposure of cells to pathogen-associated molecular patterns has yielded responses in transcription and translation that are distinct in coculture versus monoculture $[59,60]$. In the context of cytokine production and $\mathrm{T}$ cell proliferation, coculturing has yielded intriguing results in side-by-side comparisons with monoculture. For example, use of a TLR7/8-specific oligonucleotide agonist mediates a stimulatory effect on $\mathrm{CD} 4+\mathrm{T}$ cell proliferation [60]. However, when cocultured with the agonist and peripheral blood mononuclear cells the proliferation signal for $\mathrm{T}$ cells is overridden and coculture causes suppression effects via an unknown mechanism thought to involve monocyteexpressed TLR8 [60]. In a separate system of lung epithelial cells, exposure of nanoparticles in a coculture with monocyte-derived macrophages and dendritic cells showed a synergistic effect in comparison to monocultures [59]; whereas monocultures showed minor responses to inflammatory stress cocultures exhibited reduced oxidative stress and increased proinflammatory responses in this model [59].

Epithelial cell cocultures have also been used to simulate differentiation and reassortment of cells into tissue-like arrangements. These 3D organotypic models have emerged in recent decades through the usage of bioreactors and matrix gels [23]. Two types of bioreactors, namely, rotating wall models and radial flow models have been characterized and function through the use of cylindrical chambers with a central core to mediate perfusion $[23,61]$. The rotating wall bioreactor makes use of the central core to permit gas exchange while the cylinder horizontally rotates with cocultured cells and collagen-coated porous beads to initiate 3D architecture [23]. In contrast, the radial flow model utilizes the cylinder in a stationary fashion to permit media perfusion from the external membrane of the cylinder into the coculture and outwards through the membrane of the central core [62]. A 3D rotating wall bioreactor coculture of alveolar epithelial cells with macrophages was shown to mediate differentiation of monocytes into macrophagelike cells, and cause macrophages to migrate towards the epithelial layer [63]. Here, the effects of monocytes, macrophages and epithelial cells yielded a unique synergistic phenotype that afforded better protection from cytotoxininduced apoptosis [63]. Apoptosis modelling with infected epithelial and other cell types is relevant for cocultures since apoptosis is a key response of many cell types to bacteria [64-66]. Approaches towards replicating organotypic tissues with a focus on complete synthetic organ recreation are also providing glimpses into the future of organ replacement. In studies focused on liver, the use of immortalized hepatic and sinusoidal cell lines was combined in a radial flow bioreactor to replicate part of a lobe [62]. Studies of byproducts from these synthetic liver organoids have yielded varying results 
TABLe 1

\begin{tabular}{|c|c|c|c|}
\hline & Monoculture & Nonscaffolded coculture & Organotypic coculture \\
\hline Composition & Simple & Moderate, multicellular & Complex 3D, multicellular \\
\hline Interactivity & Direct response to stimulus & Synergistic/antagonistic/intercellular & $\begin{array}{l}\text { Synergistic/antagonistic/intercellul- } \\
\text { ar/stratified }\end{array}$ \\
\hline In vivo likeness & Least similar & Moderately similar & Best model of in vivo \\
\hline Technical requirements & $\begin{array}{l}\text { Simple culture and media } \\
\text { components }\end{array}$ & $\begin{array}{l}\text { Distinct media needs, no scaffolding } \\
\text { requirements }\end{array}$ & $\begin{array}{l}\text { Extensive expertise in media, culture } \\
\text { and perfusion }\end{array}$ \\
\hline Contamination & Low risk & $\begin{array}{l}\text { Moderate risk with continuous cell } \\
\text { lines }\end{array}$ & $\begin{array}{l}\text { Moderate risk with continuous cell } \\
\text { lines }\end{array}$ \\
\hline Architecture considerations & Monolayer or suspension & $\begin{array}{l}\text { Mixed monolayer, suspension, or } \\
\text { combination }\end{array}$ & $\begin{array}{l}\text { Scaffolds, gels, permeable barriers, } \\
\text { media perfusion }\end{array}$ \\
\hline
\end{tabular}

but so far indicate some key synergistic effects for drug metabolism, albumin, and urea production [20, 61, 62, 67].

An alternative form of 3D organotypic coculture uses matrix gels. These take advantage of harvesting cell lines to resuspend in collagen solutions with gelatine to form a basic 3D architecture. Using this architecture, the proximity of different cell types can be assayed for morphological changes to cell structure, or migration of cells [23]. In dentistry, the study of early tooth germ cell structure has been observed through the use of $3 \mathrm{D}$ and layered cultures that utilise dental tooth pulp and enamel epithelial cells suspended in layers that are then floated in media [68]. This resulted in a cuboidal morphology of enamel epithelial cells, which correlates with developmental effects in vivo. Here, the result would have been a simple monolayer if the epithelial cells were studied in monoculture [68]. 3D matrix gels have also demonstrated migration and differentiation when cocultured in layers. Matrix gel models in particular have been applied to intestinal studies. In one study, suspension of monocytes and intestinal fibroblasts in a collagen gel with intestinal epithelial cells led to the formation of epithelial monolayers that promoted monocyte migration and differentiation into macrophages [69]. The monocytes in this system achieved only partial maturation without the intestinal epithelial cells [69]. Thus, coculture affected not only cell-cell adhesion but also terminal cell differentiation. Synergies like these probably reflect elevated growth factor production in the media that mediates coculture-dependent cell maturation.

\subsection{Epithelial Cell Cocultures for Modelling Infectious Diseases.} Epithelial cell cocultures are increasingly being used to study host responses to infection. These models are typically based on cocultures of two host cell types and subsequent challenge with a microbial component such as membrane proteins, LPS, or cytotoxins to study virulence and pathogenesis. Whole bacteria, viruses, and parasites are also often used to challenge cocultures although this approach may be limited by microbial overgrowth. Lymphocytes, monocytes, macrophages, and natural killer cells play pivotal roles in host responses to infection, and many coculture studies have investigated the interactions of these cell types with epithelial cells. Epithelial cell-macrophage cocultures are particularly useful where there is known in situ proximity of these two cell types in vivo such as in the bladder. Different roles between macrophages and epithelial cells in tissues such as the kidneys [70], intestinal epithelium [71-74], and urogenital tissues [75] have been highlighted through different responses to cytotoxic and infectious agents. These studies have indicated the important combination of matured mononuclear cells and the surrounding epithelial cell layer in vivo in the primary response to infection (Table 1).

Contrasting results between coculture models and monocultures of macrophages or epithelial cells in infectious conditions have been shown through the use of adenoviral vectors [76, 77]. These vectors are used as vehicles for gene delivery in experimental and preclinical protocols, and encounter mixed immunological responses depending on the in vivo or in vitro setting $[76,77]$. Infection of macrophage-epithelial cell cocultures with an adenoviral vector is capable of stimulating closer in vivo-like immune responses than with macrophage or epithelial cells alone [78]. These responses, which follow proinflammatory stimulation, have been demonstrated via elevated levels of nitric oxide, reactive oxygen species, and chemokine profiles [78]. Here, IL-6 and nitric oxide responses of the coculture were reduced by $\mathrm{NF}-\mathrm{kB}$ and tyrosine kinase inhibitors, highlighting their role as inflammatory mediators [78]. Thus, epithelial cell-mononuclear cell coculture models have provided insight into immune responses to gene delivery vectors that could not be gained through the use of monocultures [78]. Additionally, they have provided key data on cell signalling effects through distinct cytokine profiles in response to infectious stimuli [79]. For example, an intestinal coculture demonstrated more limited cytokine reactivity compared to monocultures [79]. A lower response to challenge in coculture may reflect synergistic suppressive effects that occur in vivo [79]. On the other hand, the use of epithelial cells in coculture with macrophages leads to a synergistic effect on IL-10 production after infection with Escherichia coli (B Duell., unpublished observations).

An important factor that can affect experimental design and the successful application of coculture models in infection studies is the effect of microbial viability on host cell viability. Viable microbes can rapidly influence the viability of host cells through necrosis, apoptosis, and pyroptosis. As a consequence, survival rates of the cocultured cells can 
decrease rapidly [80]. While cell death is inevitable as culture media becomes spent, the input of antibiotics can kill the microbe or induce a nonreplicative viable form that can enable cocultures to be studied longer term [80]. In coculture models where pathogen viability is a consideration, preserving microbial cell structure is best addressed by the use of gamma-irradiation to inactivate the microbial cells [81]. This represents a better alternative to heat killing or UV irradiation, since both techniques denature microbial cell structures that may be important for host cell interactions $[82,83]$. Whilst all of these approaches compromise the advantages of a viable pathogen in coculture, they do provide modelling conditions not possible with the use of viable microbes where microbial overgrowth occurs. Viability is not an issue where cocultures are used to study microbial components. For example, the use of virosomes in cocultures of macrophages, epithelial cells, and dendritic cells to model lung tissue has revealed alternate cell entry mechanisms with potential applications to clinical therapies and viral pathogenesis [84]. Systems based on the use of microbial components have useful applications for studying vectors and can simulate responses to microbial epitopes without compromising viability of host cells.

\section{Conclusions}

Epithelial cell coculture models have significant benefits over monocultures, particularly in the study of infectious diseases. These models provide an important step in informing the experimental approach towards in vivo experimentation. The synergistic effects of epithelial cells with multiple cell types combined in culture can be partnered with microbial infection of cocultures to drive clinically relevant host responses. Incubation of epithelial cells with other cell types affects how the cells synthesize cytokines, induce signalling events, and differentiate. Careful selection of the cell types to use in coculture with epithelial cells and appropriate maintenance of cells is vital for suitability of coculture models. A central feature of coculture is applicability across a broad range of biological systems in addition to infectious diseases. For infection studies cocultures are essential to replicate host responses to foreign molecules, cell signalling molecules, and microbial antigens. Increased use of coculture models in the future will be necessary to discover new and more accurate in vitro synergies to unlock the complexity of in vivo biology. These models will eventually provide a more complete range of in vitro tools for experimentation, formulating the basis for translational studies with downstream clinical applications.

\section{References}

[1] M. Sundquist, A. Rydström, and M. J. Wick, "Immunity to Salmonella from a dendritic point of view," Cellular Microbiology, vol. 6, no. 1, pp. 1-11, 2004.

[2] J. J. Mans, K. von Lackum, C. Dorsey et al., "The degree of microbiome complexity influences the epithelial response to infection," BMC Genomics, vol. 10, article 380, 2009.
[3] S. C. McAllister and A. V. Moses, "Endothelial cell- and lymphocyte-based in vitro systems for understanding KSHV biology," Current Topics in Microbiology and Immunology, vol. 312, pp. 211-244, 2007.

[4] R. Bartenschlager and V. Lohmann, "Novel cell culture systems for the hepatitis C virus," Antiviral Research, vol. 52, no. 1, pp. 1-17, 2001.

[5] A. Hemphill, N. Vonlaufen, and A. Naguleswaran, "Cellular and immunological basis of the host-parasite relationship during infection with Neospora caninum," Parasitology, vol. 133, no. 3, pp. 261-278, 2006.

[6] I. M. Medana and G. D. H. Turner, "Human cerebral malaria and the blood-brain barrier," International Journal for Parasitology, vol. 36, no. 5, pp. 555-568, 2006.

[7] L. M. Friis, C. Pin, B. M. Pearson, and J. M. Wells, "In vitro cell culture methods for investigating Campylobacter invasion mechanisms," Journal of Microbiological Methods, vol. 61, no. 2, pp. 145-160, 2005.

[8] J. W. St Geme III, "Molecular and cellular determinants of non-typeable Haemophilus influenzae adherence and invasion," Cellular Microbiology, vol. 4, no. 4, pp. 191-200, 2002.

[9] A. L. Man, M. E. Prieto-Garcia, and C. Nicoletti, "Improving $\mathrm{M}$ cell mediated transport across mucosal barriers: do certain bacteria hold the keys?" Immunology, vol. 113, no. 1, pp. 1522, 2004.

[10] M. Regoli, C. Borghesi, E. Bertelli, and C. Nicoletti, "Uptake of a gram-positive bacterium (Streptococcus pneumoniae R36a) by the M cells of rabbit Peyer's patches," Annals of Anatomy, vol. 177, no. 2, pp. 119-124, 1995.

[11] P. Tyrer, A. R. Foxwell, A. W. Cripps, M. A. Apicella, and J. M. Kyd, "Microbial pattern recognition receptors mediate M-cell uptake of a gram-negative bacterium," Infection and Immunity, vol. 74, no. 1, pp. 625-631, 2006.

[12] A. Sayi, E. Kohler, I. M. Toller et al., "TLR-2-activated B cells suppress Helicobacter-induced preneoplastic gastric immunopathology by inducing T regulatory-1 cells," Journal of Immunology, vol. 186, no. 2, pp. 878-890, 2011.

[13] F. Bihl, J. Pecheur, B. Bréart et al., "Primed antigen-specific $\mathrm{CD}^{4+} \mathrm{T}$ cells are required for NK cell activation in vivo upon Leishmania major infection," Journal of Immunology, vol. 185, no. 4, pp. 2174-2181, 2010.

[14] H. Yoo, S. H. Park, S. K. Ye, and M. Kim, "IFN- $\gamma$-induced BST2 mediates monocyte adhesion to human endothelial cells," Cell Immunology, vol. 267, no. 1, pp. 23-29, 2011.

[15] P. C. Delekta, I. J. Apel, S. Gu et al., “Thrombin-dependent NF$\kappa \mathrm{b}$ activation and monocyte/endothelial adhesion are mediated by the CARMA3-Bcl10-MALT1 signalosome," Journal of Biological Chemistry, vol. 285, no. 53, pp. 41432-41442, 2010.

[16] G. C. Ulett, N. Ketheesan, and R. G. Hirst, "Macrophagelymphocyte interactions mediate anti-Burkholderia pseudomallei activity," FEMS Immunology and Medical Microbiology, vol. 21, no. 4, pp. 283-286, 1998.

[17] P. Tippayawat, M. Pinsiri, D. Rinchai et al., "Burkholderia pseudomallei proteins presented by monocyte-derived dendritic cells stimulate human memory T cells in vitro," Infection and Immunity, vol. 79, no. 1, pp. 305-313, 2011.

[18] M. C. Berin, D. M. McKay, and M. H. Perdue, "Immuneepithelial interactions in host defense," American Journal of Tropical Medicine and Hygiene, vol. 60, no. 4, pp. 16-25, 1999.

[19] A. D. Lehmann, N. Daum, M. Bur, C.-M. Lehr, P. Gehr, and B. M. Rothen-Rutishauser, "An in vitro triple cell co-culture model with primary cells mimicking the human alveolar epithelial barrier," European Journal of Pharmaceutics and Biopharmaceutics, vol. 77, no. 3, pp. 398-406, 2011. 
[20] R. Saito, Y. Ishii, R. Ito et al., "Transplantation of liver organoids in the omentum and kidney," Artificial Organs, vol. 35, no. 1, pp. 80-83, 2011.

[21] C. A. Nickerson, E. G. Richter, and C. M. Ott, "Studying hostpathogen interactions in 3-D: organotypic models for infectious disease and drug development," Journal of Neuroimmune Pharmacology, vol. 2, no. 1, pp. 26-31, 2007.

[22] N. Jacobs, M. P. Moutschen, E. Franzen-Detrooz, V. Boniver, J. Boniver, and P. Delvenne, "Organotypic culture of HPVtransformed keratinocytes: a model for testing lymphocyte infiltration of (pre)neoplastic lesions of the uterine cervix," Virchows Archiv, vol. 432, no. 4, pp. 323-330, 1998.

[23] J. Barrila, A. L. Radtke, A. Crabbé et al., "Organotypic 3D cell culture models: using the rotating wall vessel to study hostpathogen interactions," Nature Reviews Microbiology, vol. 8, no. 11, pp. 791-801, 2010.

[24] Z. Zhang, A. J. McGoron, E. T. Crumpler, and C. Z. Li, "Coculture based blood-brain barrier in vitro model, a tissue engineering approach using immortalized cell lines for drug transport study," Applied Biochemistry and Biotechnology, vol. 163, no. 2, Article ID 278295, 18 pages, 2011.

[25] Y. Y. Li, J. W. C. Chang, L. L. Hsieh, and K. Y. Yeh, "Neutralization of interleukin (IL)-10 released by monocytes/macrophages enhances the up-regulatory effect of monocyte/macrophage-derived IL-6 on expressions of IL-6 and MUC1, and migration in HT-29 colon cancer cells," Cellular Immunology, vol. 265, no. 2, pp. 164-171, 2010.

[26] A. Elkhal, L. Tunggal, and M. Aumailley, "Fibroblasts contribute to the deposition of laminin 5 in the extracellular matrix," Experimental Cell Research, vol. 296, no. 2, pp. 223230, 2004.

[27] A. Seltana, N. Basora, and J. F. Beaulieu, "Intestinal epithelial wound healing assay in an epithelial-mesenchymal co-culture system," Wound Repair and Regeneration, vol. 18, no. 1, pp. 114-122, 2010.

[28] B. A. Conway-Myers, "Co-culture update: creating an embryotrophic environment in vitro," Seminars in Reproductive Endocrinology, vol. 16, no. 3, pp. 175-182, 1998.

[29] N. M. Orsi and J. B. Reischl, "Mammalian embryo coculture: trials and tribulations of a misunderstood method," Theriogenology, vol. 67, no. 3, pp. 441-458, 2007.

[30] M. Butler, Animal Cell Culture and Technology, BIOS Scientific Publishers, London, UK, 2nd edition, 2004.

[31] J. Hytönen, S. Haataja, and J. Finne, "Streptococcus pyogenes glycoprotein-binding strepadhesin activity is mediated by a surface-associated carbohydrate-degrading enzyme, pullulanase," Infection and Immunity, vol. 71, no. 2, pp. 784-793, 2003.

[32] M. R. Nokhbeh, S. Hazra, D. A. Alexander et al., "Enterovirus 70 binds to different glycoconjugates containing $\alpha 2,3$-linked sialic acid on different cell lines," Journal of Virology, vol. 79, no. 11, pp. 7087-7094, 2005.

[33] A. W. Paton, R. Morona, and J. C. Paton, "Bioengineered bugs expressing oligosaccharide receptor mimics: toxin-binding probiotics for treatment and prevention of enteric infections," Bioengineered Bugs, vol. 1, no. 3, pp. 172-177, 2010.

[34] O. Fumagalli, B. D. Tall, C. Schipper, and T. A. Oelschlaeger, "N-glycosylated proteins are involved in efficient internalization of Klebsiella pneumoniae by cultured human epithelial cells," Infection and Immunity, vol. 65, no. 11, pp. 4445-4451, 1997.

[35] J. Mahdavi, B. Sondén, M. Hurtig et al., "Helicobacter pylori sabA adhesin in persistent infection and chronic inflammation," Science, vol. 297, no. 5581, pp. 573-578, 2002.
[36] D. J. Holt, L. M. Chamberlain, and D. W. Grainger, "Cellcell signaling in co-cultures of macrophages and fibroblasts," Biomaterials, vol. 31, no. 36, pp. 9382-9394, 2010.

[37] Z. L. Dai, X. L. Li, P. B. Xi, J. Zhang, G. Wu, and W. Y. Zhu, "Metabolism of select amino acids in bacteria from the pig small intestine," Amino Acids. In press.

[38] A. K. Johri, V. Patwardhan, and L. C. Paoletti, "Growth rate and oxygen regulate the interactions of group B Streptococcus with polarized respiratory epithelial cells," Canadian Journal of Microbiology, vol. 51, no. 4, pp. 283-286, 2005.

[39] A. Bernhardt, D. Kuester, A. Roessner, T. Reinheckel, and S. Krueger, "Cathepsin X-deficient gastric epithelial cells in co-culture with macrophages: characterization of cytokine response and migration capability after Helicobacter pylori infection," Journal of Biological Chemistry, vol. 285, no. 44, pp. 33691-33700, 2010.

[40] R. Rochford, M. J. Cannon, R. E. Sabbe et al., "Common and idiosyncratic patterns of cytokine gene expression by EpsteinBarr virus transformed human B cell lines," Viral Immunology, vol. 10, no. 4, pp. 183-195, 1997.

[41] J. Finke, P. Ternes, W. Lange, R. Mertelsmann, and G. Dolken, "Expression of interleukin 10 in B lymphocytes of different origin,” Leukemia, vol. 7, no. 11, pp. 1852-1857, 1993.

[42] T. T. Sun, H. Zhao, J. Provet, U. Aebi, and X. R. Wu, "Formation of asymmetric unit membrane during urothelial differentiation," Molecular Biology Reports, vol. 23, no. 1, pp. 3-11, 1996.

[43] X. R. Wu, J. H. Lin, T. Walz et al., "Mammalian uroplakins. A group of highly conserved urothelial differentiation-related membrane proteins," Journal of Biological Chemistry, vol. 269, no. 18, pp. 13716-13724, 1994.

[44] A. N. Mabbett, G. C. Ulett, R. E. Watts et al., "Virulence properties of asymptomatic bacteriuria Escherichia coli," International Journal of Medical Microbiology, vol. 299, no. 1, pp. 53-63, 2009.

[45] J. Valle, A. N. Mabbett, G. C. Ulett et al., "UpaG, a new member of the trimeric autotransporter family of adhesins in uropathogenic Escherichia coli," Journal of Bacteriology, vol. 190, no. 12, pp. 4147-4161, 2008.

[46] G. C. Ulett, R. I. Webb, K. B. Ulett et al., "Group B Streptococcus (GBS) urinary tract infection involves binding of GBS to bladder uroepithelium and potent but GBS-specific induction of interleukin 1 $\alpha$," Journal of Infectious Diseases, vol. 201, no. 6, pp. 866-870, 2010.

[47] E. D. Lobban, B. A. Smith, G. D. Hall et al., "Uroplakin gene expression by normal and neoplastic human urothelium," American Journal of Pathology, vol. 153, no. 6, pp. 1957-1967, 1998.

[48] J. Olsburgh, P. Harnden, R. Weeks et al., "Uroplakin gene expression in normal human tissues and locally advanced bladder cancer," Journal of Pathology, vol. 199, no. 1, pp. 4149, 2003.

[49] K. Ogawa, T. T. Sun, and S. M. Cohen, "Analysis of differentiation-associated proteins in rat bladder carcinogenesis," Carcinogenesis, vol. 17, no. 5, pp. 961-965, 1996.

[50] Y. C. Smith, K. K. Grande, S. B. Rasmussen, and A. D. O'Brien, "Novel three-dimensional organoid model for evaluation of the interaction of uropathogenic Escherichia coli with terminally differentiated human urothelial cells," Infection and Immunity, vol. 74, no. 1, pp. 750-757, 2006.

[51] B. P. Lucey, W. A. Nelson-Rees, and G. M. Hutchins, "Henrietta Lacks, HeLa cells, and cell culture contamination," 
Archives of Pathology and Laboratory Medicine, vol. 133, no. 9, pp. 1463-1467, 2009.

[52] M. Lacroix, "Persistent use of "false" cell lines," International Journal of Cancer, vol. 122, no. 1, pp. 1-4, 2008.

[53] J. G. Rasmussen, O. Frøbert, L. Pilgaard et al., "Prolonged hypoxic culture and trypsinization increase the pro-angiogenic potential of human adipose tissue-derived stem cells," Cytotherapy, vol. 13, no. 3, pp. 318-328, 2011.

[54] M. Okamura, N. Yokoyama, N. Takabatake, K. Okubo, Y. Ikehara, and I. Igarashi, "Modification of host erythrocyte membranes by trypsin and chymotrypsin treatments and effects on the in vitro growth of bovine and equine Babesia parasites," Journal of Parasitology, vol. 93, no. 1, pp. 208-211, 2007.

[55] R. Matěj, P. Manďáková, I. Netíková, P. Poučková, and T. Olejár, "Proteinase-activated receptor-2 expression in breast cancer and the role of trypsin on growth and metabolism of breast cancer cell line MDA MB-231," Physiological Research, vol. 56, no. 4, pp. 475-484, 2007.

[56] A. Bengrine, J. Li, L. L. Hamm, and M. S. Awayda, "Indirect activation of the epithelial $\mathrm{Na}^{+}$channel by trypsin," Journal of Biological Chemistry, vol. 282, no. 37, pp. 26884-26896, 2007.

[57] L. C. Hendricks, S. L. McClanahan, G. E. Palade, and M. G. Farquhar, "Brefeldin A affects early events but does not affect late events along the exocytic pathway in pancreatic acinar cells," Proceedings of the National Academy of Sciences of the United States of America, vol. 89, no. 15, pp. 7242-7246, 1992.

[58] A. Dinter and E. G. Berger, "Golgi-disturbing agents," Histochemistry and Cell Biology, vol. 109, no. 5-6, pp. 571-590, 1998.

[59] L. Müller, M. Riediker, P. Wick, M. Mohr, P. Gehr, and B. Rothen-Rutishauser, "Oxidative stress and inflammation response after nanoparticle exposure: differences between human lung cell monocultures and an advanced threedimensional model of the human epithelial airways," Journal of the Royal Society Interface, vol. 7, no. 1, pp. S27-S40, 2010.

[60] D. Richardt-Pargmann, M. Wechsler, A. M. Krieg, J. Vollmer, and M. Jurk, "Positive T cell co-stimulation by TLR7/8 ligands is dependent on the cellular environment," Immunobiology, vol. 216, no. 1-2, pp. 12-23, 2011.

[61] S. Nagamori, S. Hasumura, T. Matsuura, H. Aizaki, and M. Kawada, "Developments in bioartificial liver research: concepts, performance, and applications," Journal of Gastroenterology, vol. 35, no. 7, pp. 493-503, 2000.

[62] M. Saito, T. Matsuura, T. Masaki et al., "Reconstruction of liver organoid using a bioreactor," World Journal of Gastroenterology, vol. 12, no. 12, pp. 1881-1888, 2006.

[63] A. Crabbé, S. F. Sarker, R. Van Houdt et al., "Alveolar epithelium protects macrophages from quorum sensing-induced cytotoxicity in a three-dimensional co-culture model," Cellular Microbiology, vol. 13, no. 3, pp. 469-481, 2011.

[64] G. C. Ulett and E. E. Adderson, "Regulation of apoptosis by gram-positive bacteria: mechanistic diversity and consequences for immunity," Current Immunology Reviews, vol. 2, no. 2, pp. 119-141, 2006.

[65] G. C. Ulett and E. E. Adderson, "Nitric oxide is a key determinant of group B Streptococcus-induced murine macrophage apoptosis," Journal of Infectious Diseases, vol. 191, no. 10, pp. 1761-1770, 2005.

[66] G. C. Ulett, J. F. Bohnsack, J. Armstrong, and E. E. Adderson, " $\beta$-hemolysin-independent induction of apoptosis of macrophages infected with serotype III group B Streptococcus," Journal of Infectious Diseases, vol. 188, no. 7, pp. 1049-1053, 2003.
[67] T. Iwahori, T. Matsuura, H. Maehashi et al., "CYP3A4 inducible model for in vitro analysis of human drug metabolism using a bioartificial liver," Hepatology, vol. 37, no. 3, pp. 665673, 2003.

[68] T. Notani, M. J. Tabata, H. Iseki, O. Baba, and Y. Takano, "Introduction of a three-dimensional and layered (TDL) culture, a novel primary co-culture method for ameloblasts and pulp-derived cells," Archives of Histology and Cytology, vol. 72, no. 3, pp. 187-198, 2009.

[69] T. Spottl, M. Hausmann, M. Gunckel et al., "A new organotypic model to study cell interactions in the intestinal mucosa," European Journal of Gastroenterology and Hepatology, vol. 18, no. 8, pp. 901-909, 2006.

[70] V. A. Patel, D. J. Lee, A. Longacre-Antoni et al., "Apoptotic and necrotic cells as sentinels of local tissue stress and inflammation: response pathways initiated in nearby viable cells review," Autoimmunity, vol. 42, no. 4, pp. 317-321, 2009.

[71] D. E. Bockman, W. R. Boydston, and D. H. Beezhold, "The role of epithelial cells in gut-associated immune reactivity," Annals of the New York Academy of Sciences, vol. 409, pp. 129-144, 1983.

[72] D. M. Bull and M. A. Bookman, "Isolation and functional characterization of human intestinal mucosal lymphoid cells," Journal of Clinical Investigation, vol. 59, no. 5, pp. 966-974, 1977.

[73] J. P. Golder and W. F. Doe, "Isolation and preliminary characterization of human intestinal macrophages," Gastroenterology, vol. 84, no. 4, pp. 795-802, 1983.

[74] P. Sansonetti, "Phagocytosis of bacterial pathogens: implications in the host response," Seminars in Immunology, vol. 13, no. 6, pp. 381-390, 2001.

[75] C. R. Wira, J. V. Fahey, C. L. Sentman, P. A. Pioli, and L. Shen, "Innate and adaptive immunity in female genital tract: cellular responses and interactions," Immunological Reviews, vol. 206, pp. 306-335, 2005.

[76] N. Brunetti-Pierri and P. Ng, "Progress and prospects: gene therapy for genetic diseases with helper-dependent adenoviral vectors," Gene Therapy, vol. 15, no. 8, pp. 553-560, 2008.

[77] S. K. Campos and M. A. Barry, "Current advances and future challenges in adenoviral vector biology and targeting," Current Gene Therapy, vol. 7, no. 3, pp. 189-204, 2007.

[78] B. H. Lee, R. Kushwah, J. Wu et al., "Adenoviral vectors stimulate innate immune responses in macrophages through cross-talk with epithelial cells," Immunology Letters, vol. 134, no. 1, pp. 93-102, 2010.

[79] E. Van Hoffen, N. M. Korthagen, S. De Kivit et al., "Exposure of intestinal epithelial cells to UV-killed lactobacillus GG but not bifidobacterium breve enhances the effector immune response in vitro," International Archives of Allergy and Immunology, vol. 152, no. 2, pp. 159-168, 2010.

[80] C. Wiegand, M. Abel, P. Ruth, and U. C. Hipler, "HaCaT keratinocytes in co-culture with Staphylococcus aureus can be protected from bacterial damage by polihexanide," Wound Repair and Regeneration, vol. 17, no. 5, pp. 730-738, 2009.

[81] A. Trampuz, K. E. Piper, J. M. Steckelberg, and R. Patel, "Effect of gamma irradiation on viability and DNA of Staphylococcus epidermidis and Escherichia coli," Journal of Medical Microbiology, vol. 55, no. 9, pp. 1271-1275, 2006.

[82] A. Ruiz-Bravo, C. Bujalance, F. Romero, E. Moreno, and M. Jimenez-Valera, "Immunomodulation by Yersinia enterocolitica: comparison of live and heat-killed bacteria," FEMS Immunology and Medical Microbiology, vol. 39, no. 3, pp. 229233, 2003. 
[83] K. L. Bost, J. L. Bento, C. C. Petty, L. W. Schrum, M. C. Hudson, and I. Marriott, "Monocyte chemoattractant protein-1 expression by osteoblasts following infection with Staphylococcus aureus or Salmonella," Journal of Interferon and Cytokine Research, vol. 21, no. 5, pp. 297-304, 2001.

[84] U. Hofer, A. D. Lehmann, E. Waelti, M. Amacker, P. Gehr, and B. Rothen-Rutishauser, "Virosomes can enter cells by nonphagocytic mechanisms U. Hofer et al," Journal of Liposome Research, vol. 19, no. 4, pp. 301-309, 2009. 


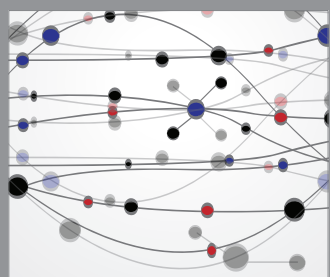

The Scientific World Journal
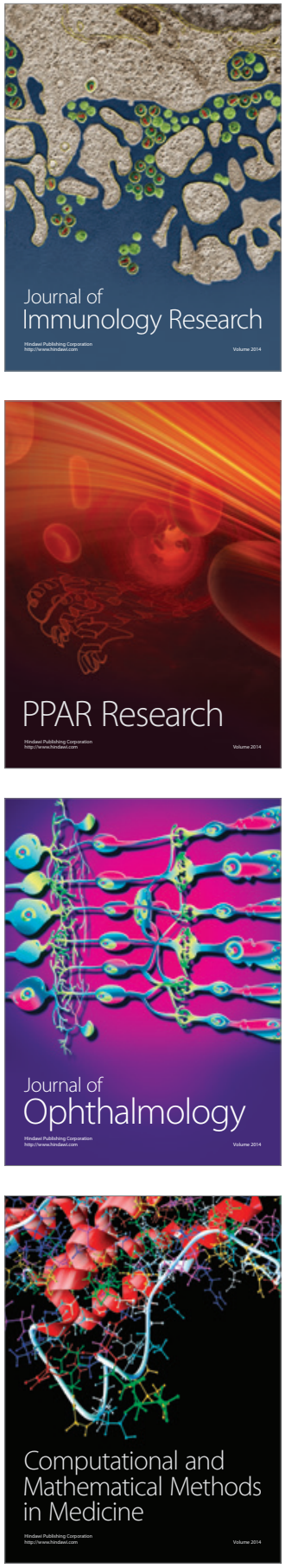

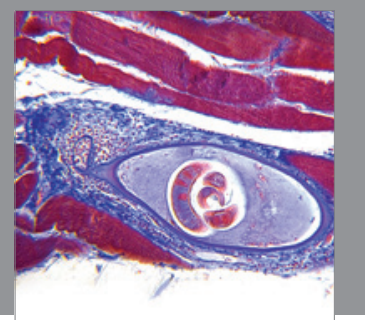

Gastroenterology

Research and Practice
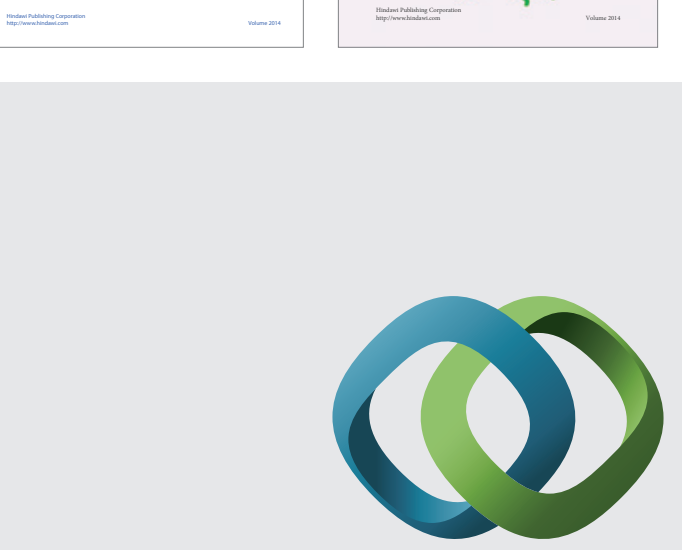

\section{Hindawi}

Submit your manuscripts at

http://www.hindawi.com
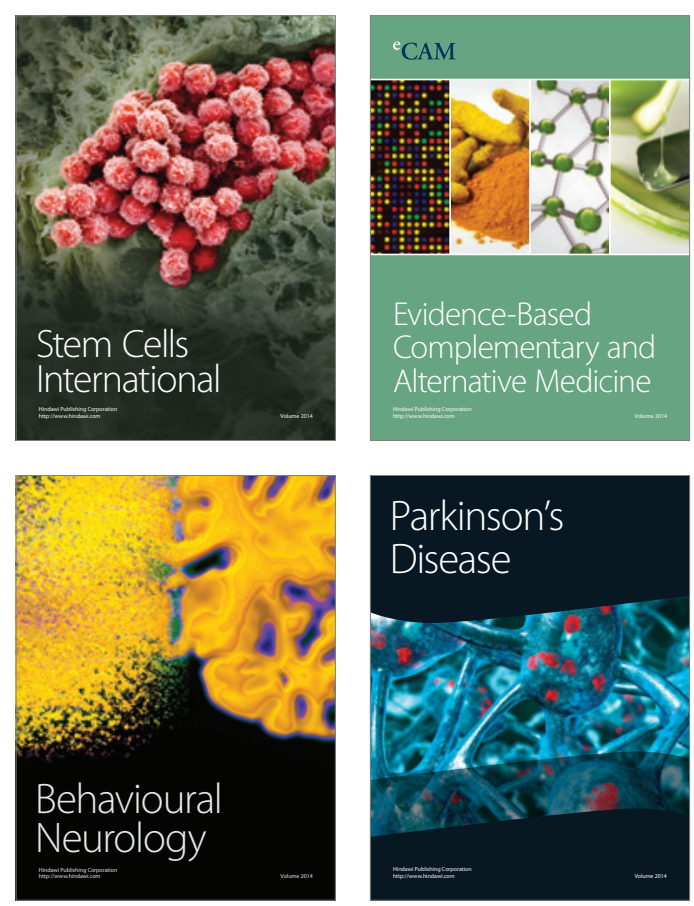

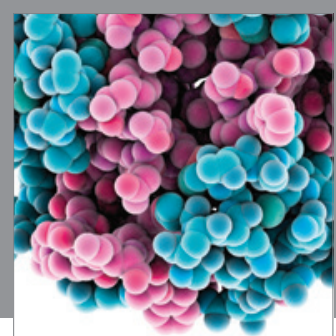

Journal of
Diabetes Research

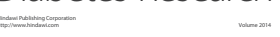

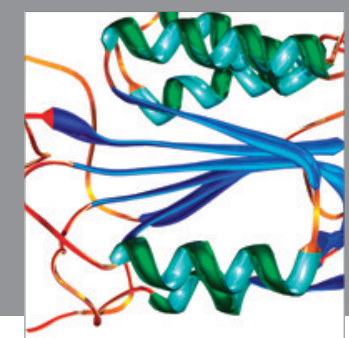

Disease Markers
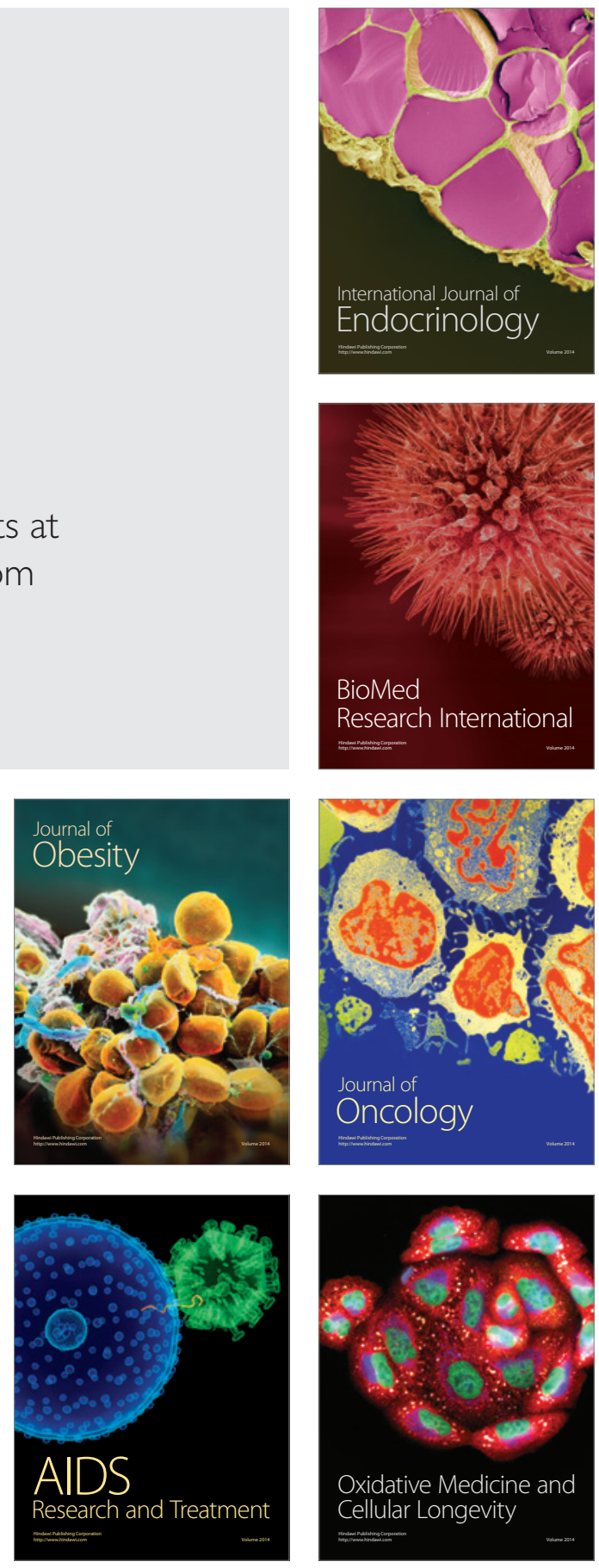